\title{
Analysis on Thoughts of Enhancing Piano Performance Teaching
}

\author{
Xiaoxia Zhang \\ Hebei North University, Zhangjiakou, 075000, China
}

\begin{abstract}
Keywords: piano performance; teaching; thoughts
\end{abstract}
\begin{abstract}
With continuous development of Chinese economic society, people's musical appreciation ability is also continuously improved, thus it is required to pay attention to improving students' professional level and performance ability in piano teaching of higher education institutions. Therefore, implementing successful piano performance teaching to improve learners' professional level has become one of important tasks in piano teaching. This paper analyzes the thoughts of enhancing piano performance teaching from 5 aspects, that is, to help students to feel creation background and style of musical works, to guide students to master basic piano performance skills, to meticulously handle music performance, to pay attention to tone teaching of piano performance, and to carry out imagination with rich artistic conception.
\end{abstract}

\section{Introduction}

The piano performance is a refined art activity full of challenges and creativities, and the creation form of this art mainly depends on feelings and musical instrument to implement artistic production, that is, in piano performance, the artistic creation is implemented mainly by virtue of technology and expressive force. After the technical problem is solved, the excellent expressive force of piano performance is also required. Specifically speaking, how shall we cultivate students' piano performance ability? The author thinks that the following points shall be done.

\section{To help students to feel creation background and style of musical works}

Firstly, it is required to accurately know the creation background of music to be performed. Each piece of music work is the reproduction and expression of the composer's emotional experience in inner world; only after we understand and master the internal affection of music work, our performance can have vitality and infectivity. In view of this, in the piano teaching process, the teachers shall explain the composer's living age, creation background of this work, and other contents to the students so that the students can get a deeper understanding of relevant situations of the work and the composer's creation intention, and then can understand musical work from theoretical level. Secondly, it is required to let learners feel unique style of musical works. Letting students learn how to listen to music is the most ideal means to feel unique style of musical works. Therefore, in the teaching process, the teachers shall often remind students of listening to musical works, and let students learn to distinguish whether the music they perform is pleasant to the ears and carefully feel the slight change of sound at levels. Thirdly, the teachers shall guide learners to listen to various kinds of musical works with different style. Through listening to famous piano performers' excellent performance, it is able to let learners feel the sense of beauty brought by the music and feel bright style of musical works in listening process, such as Chopin's elegant and gorgeous style, Mozart's bright and clear style, and Liszt's passionate and bold style. In this way, it is able to let students have own feelings in terms of understanding of musical works and then make preparation for acutely performing the music.

\section{To guide students to master basic piano performance skills}

Firstly, it is required to have specific aim. It is required to let students clearly know outstanding position of skills in performance, specify skill teaching goal which conforms to actual situation, and encourage each student to actively and persistently take training. 
Secondly, it is required to pay attention to practice of basic skills of piano performance. This teaching link requires to make efforts from most fundamental sitting position. The teachers shall guide students to make performance under a state of relaxed mind and body, carefully observe and analyze the skill error which may happen in learners' performance process and the reason, and timely adopt more active and effective measures to correct and guide various kinds of skill errors which may happen in performance so as to let students develop a good performance habit and then lay a good foundation for their performance of musical works.

Thirdly, it is required to accurately read the music score. Many students only pay attention to whether the pitch and rhythm of musical works are correct; actually, except for those details, there are still large quantity of important marks which directly or indirectly influence students' understanding of music and mastering of style. For example, the musical terms prompt that the style of this music is happy or sad, allegro or adagio, andante, which will directly influence the mastering of style and performance effect. Furthermore, the attention shall be also paid to fingering. Once the students don't pay attention to hints in music score, but arbitrarily and flexibly select corresponding fingering; after they enter into examination room, stage or other specific environment, they will become nervous due to inconsistency with memory at ordinary times, thus some problems may happen, and even the performance may fail. Therefore, before being familiar with music score, the performers shall carefully read the score, be careful to all marks on score, and seize the main emotion of this musical work on this basis so as to perform original artistic conception of the work to maximum degree.

Fourthly, it is required to cultivate piano sight-playing ability, which is one of piano performance skills together with sight-reading and playing. Actively cultivating students' piano sight-playing ability can be said an extremely important but difficult problem in piano teaching. The sight-playing is not only the basic skill of piano performance, but also one of important means for students to check creation and read piano music literature. Once the performers can't make sight playing but depend on recited playing, their piano learning ability will be limited and their musical view can't be expanded. In view of this, utilizing sight-playing teaching to cultivate students' sight-playing ability is very important for improving students' ability to learn piano, and also very important for them to improve their music quality. In teaching process, especially in cultivating professional piano talents-oriented classroom teaching process, if the teachers don't list sight playing into key teaching point or ignore this point in teaching, it is unable to satisfactorily complete the objective of teaching task.

\section{To meticulously handle music performance}

Firstly, the attention shall be paid to musical form analysis and music study in teaching. Large number of performers have superficial research on musical form structure and music requirements; therefore, in performance process, it is very easy for them not to realize most ideal effect in the transition, joint, and layering sense. Meanwhile, due to development of postmodernism thoughts, a trend of re-interpreting and re-constructing previous masters' works, including classical music, has been formed in international environment. The essence of piano performance is a kind of second recreation; therefore, the performers in each era will inject their knowledge and expression into the works so as to show the performers' performance features.

Secondly, it is required to clearly explain the property of music. In the processing of handling musical works, it is not only required to emphasize phrases and fragments, but also required to emphasize the main melody; what's more, the attention shall be paid to musical artistic conception and musical image. We shall tightly seize the quintessence of musical works, and master it from thoughts and feelings; in this way, the performance can be more vivid and full of sense of layering. In view of this, as for teaching of any musical work, no matter what size the music is, the teachers shall firstly analyze whether the content to be expressed is happy or sad, excited or disappointed for the students, and shall also point out which means can be used to realize performance purpose.

Thirdly, it is required to explain the connotation of each phrase and let students know which actions are used to make performance in the process of guiding students to handle music. Each 
phrase has starting part, climax part, and ending part; the teachers shall guide students to learn how to listen to and understand the music, and then apply reasonable actions to show each part of music. In the climax part, it is required to quicken the step or slightly improve the sound so as to realize proper effect. The situation is opposite for the process from climax to end. As long as we can properly handle slight changes in those musical works and apply suitable proportion, the phrases can be endowed with new vitality to conform to naturally revealed musical sensibility and greatly improve expressive force of music. As for partial musical works, the setting shall be made according to musical works; the slight slow-in and slow-out are allowed, but they shall be carefully applied to realize natural effect. Through training, the learners shall be able to feel which places are right and which places are problematic for music; in this way, the expressive force of music can be perfectly shown.

\section{To pay attention to tone teaching of piano performance}

The piano performance is an important performance art, and the primary factor is tone. The melody is the important foundation and necessary condition for musical creation, while the tone is the primary factor in implementation of music performance. If one excellent piano musical work lacks of pure and beautiful tone as carrier, it is failed work and it is difficult to motivate modern people's taste, interest, and resonance. Therefore, the primary factor of piano performance is good tone. After confirmation of concept and origin of excellent tone of piano, it is required to further enter into specific operation of piano performance, and learn to apply scientific, standard, and reasonable technical method to obtain beautiful piano performance tone. According to the author's teaching feelings, in order to obtain good piano performance tone, the teachers shall guide students to pay attention to following 2 aspects in basic stage.

On one hand, it is required to master correct performance posture. This is the primary operation procedure for learners to obtain beautiful tone. The piano is performed mainly via a way of sitting posture; therefore, from perspective of sitting posture, the performers' body shall be upright, the waist and back shall be straight and upright, and a reasonable and suitable natural bending shall be made so as to keep body under active and relaxed state, and it is also required to let center of body weight slightly incline forwards; in this way, it is good for performers' body to move forwards, backwards, rightwards, and leftwards, and also good for piano playing by virtue of body weight. Meanwhile, it is required to keep reasonable distance with piano and desk height so as to let the body keep stable and flexible, and also create a better condition for performers' forwards, backwards, rightwards, and leftwards movement, both hands' quick playing and cross playing.

On the other hand, the accurate figure posture and key touching are required. Whether the figure posture and key touching are correct is very important in piano performance. The piano depends on performer's fingers to tap the keys to make a musical sound; through direct finger tapping on keys, various kinds of mechanical devices in the piano are driven, and then the sound is made via linkage reaction; therefore, the fingers which directly contact the keys become very important, and the production of sound directly originates from key touching. In view of this, the scientific and reasonable figure posture and key touching can accurately express performers' intention, and fully show unique and touching tone of piano, flexible expressive force, and diversified features. The performers' correct finger posture shall be that the fingers naturally bend as arc shape so as to form a shape of holding ball; all phalangeal joints shall suitably heave, which not only can realize more natural and convenient key touching, but also can let fingers move in a more flexible and quick way. Meanwhile, upon key touching, the performers' palm shape shall be unable to support finger top, and the palm shall be basically able to vertically stand above the plane of keys; the third joint drives upward and downward movements of, and the performers' $2^{\text {nd }} \sim 5^{\text {th }}$ finger basically shall vertically stand on the plane of keys. After the performers lift their hands, they shall press the keys firmly; the fingers shall stand vertically with moderate force; the keys shall be pressed to the bottom, and the scientific and reasonable key touching is also an important basis of piano performance. In view of this, in order to have good performance tone, the learners shall master correct method and gradually make learning. This is not only the primary factor for students to further learn piano performance, 
but also an important goal that the performers devote to seeking for and perfecting in learning process.

\section{To carry out imagination with rich artistic conception}

The imagination is a psychological process in which people analyze and comprehensively process memory and presentation in their brain to form a brand-new presentation. It is a kind of special form of thinking. Similarly, the piano performance is an imagination process to reproduce musicians' thoughts, style, and living scenes, etc. Therefore, in the teaching, the piano teachers shall give priority to select visual works to let students make performance so as to guide and encourage them to express music by use of imagination, let music become more vivid, let works shown before modern people in a vivid way, and let learners deeply feel beauty of piano performance. As for those young students with easy experiences, the teachers shall actively encourage the students to seek for reasonable plots and imagine out wonderful stories in the process of musical practice, as well as make enlightenments and induction. The classical composers are far way modern people's life, thus it is unnecessary to let students feel the works fully according to current time background, and the students can imagine stories according to their living environment, experiences, and emotional experiences. For example, when the teachers guide students to play Beethoven's famous music For Elise, the teachers can enlighten students to dedicate this music to their parents or teachers; if students can apply this plot to make performance, they will become more concentrated and the music will become more beautiful. The teachers shall require students to make performance with plots; in this way, the students will not feel boring, and may change the interest into fun to create better artistic conception of performance.

\section{Conclusion}

To sum up, the piano performance skills are only the content at physical level in the art. Any piano performer shall try their best to seek for highly difficult skills to obtain best performance effect; however, a person who only depends on skills can't become a performer. The piano performance is a kind of artistic form full of emotional expressive force, thus the performance personnel shall be full of enthusiasm. Therefore, the piano instructors shall enhance guide from perspective of skills, tone, and musicality to realize effective combination of performance skills and emotional expressive force so as to perform beautiful music.

\section{References}

[1] Han Dong: Discussion on Playing and Performance in Piano Teaching [J], Music Life, 2012 (10).

[2] Zhou Dan: Discussion on Training of Basic Performance Skills in Piano Teaching [J], Education for Chinese After-school, 2012 (11).

[3] Lu Ling: Demonstrative Performance in Piano Teaching [J], Chinese Music, 2013 (1).

[4] Zhang Ying: Discussion on How to Improve Students' Performance Ability in Piano Teaching [J], Art Science and Technology, 2014 (2).

[5] Li Xintong: Analysis on Design and Teaching Reform of Piano Performance Course in Colleges and Universities [J], Yellow River Sound, 2014 (6). 